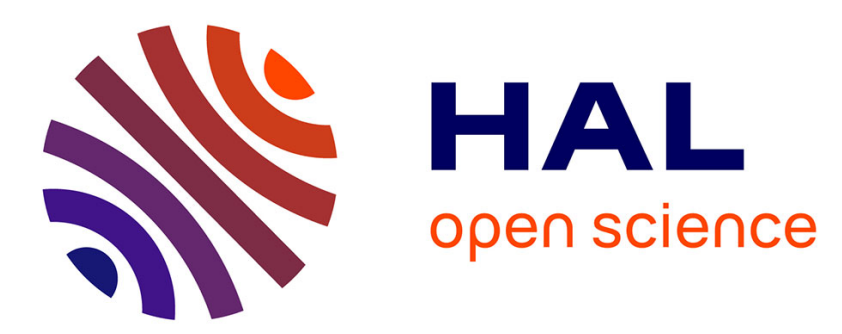

\title{
Combined influence of expertise and fatigue on riding strategy and horse-rider coupling during the time course of endurance races
}

S Viry, J B de Graaf $\dagger$, J-P Frances, Eric Berton, M Laurent, C Nicol

\section{- To cite this version:}

S Viry, J B de Graaf $\dagger$, J-P Frances, Eric Berton, M Laurent, et al.. Combined influence of expertise and fatigue on riding strategy and horse-rider coupling during the time course of endurance races. Equine Veterinary Journal, 2014, 47 (1), pp.78 - 82. 10.1111/evj.12236 . hal-01454884

\author{
HAL Id: hal-01454884 \\ https://hal.science/hal-01454884
}

Submitted on 22 Nov 2017

HAL is a multi-disciplinary open access archive for the deposit and dissemination of scientific research documents, whether they are published or not. The documents may come from teaching and research institutions in France or abroad, or from public or private research centers.
L'archive ouverte pluridisciplinaire HAL, est destinée au dépôt et à la diffusion de documents scientifiques de niveau recherche, publiés ou non, émanant des établissements d'enseignement et de recherche français ou étrangers, des laboratoires publics ou privés. 


\title{
Combined influence of expertise and fatigue on riding strategy and horse-rider coupling during the time course of endurance races
}

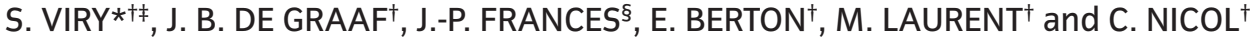 \\ ${ }^{\dagger}$ Aix-Marseille Université, CNRS, Institut des Sciences du Mouvement, UMR 7287, Marseille, France \\ ¥BRD Concept, Anglet, France \\ §.JPF Stables, Venelles, France.
}

*Correspondence email: s.viry@brdconcept.fr; Received: 07.08.13; Accepted: 26.01.14

\begin{abstract}
Summary
Reasons for performing study: The relationship between the biomechanical horse-rider interaction and endurance race performance requires further investigation.

Objectives: To characterise, both quantitatively and qualitatively, elite and advanced horse-rider dyads on the basis of the biomechanical horse-rider interaction during endurance races.

Study design: Five elite and 5 advanced horse-rider dyads were recorded during CEI*/CE|** endurance races using 2 synchronised triaxial accelerometers each placed close to horse and rider centres of mass.

Methods: For each horse-rider dyad, analyses focused on the vertical displacements of horse and rider per stride. This allowed quantification of the proportional use of each gait and riding technique per loop. The quality of the biomechanical horse-rider interaction was examined through the relative phases (RP) of their respective vertical displacement minima. Instantaneous speed and rider heart rates were recorded using a global positioning system device/heart rate monitor.

Results: All dyads predominantly used 2 riding techniques per gait. The 2-point trot proportion was limited in both groups (11\%). Throughout the race, the advanced horse-rider dyads showed a global stability in speed, in the proportion of 4 combinations of gait and riding techniques and in mean RP. However, the elite horse-rider dyads initially had higher mean RP values $(\mathrm{P}<0.01)$, and from mid-race to the end an increasing proportion of sitting canter, with associated increases in racing speed $(P<0.001)$ and in mean heart rate $(P<0.01)$. Intradyad RP variability in 2-point canter increased in both groups $(P<0.01)$. Conclusions: Accelerometers are a valuable tool to follow the quantitative and qualitative trends of the biomechanical horse-rider interaction during international endurance races. The overall results emphasise the influence of the level of expertise on the adopted gait and riding techniques, thus influencing the racing speed. It remains to be established whether fatigue and/or strategy underlie our observations.
\end{abstract}

Keywords: horse; horse-rider; coordination; endurance race; expertise; fatigue

\section{Introduction}

In endurance races, while trying to minimise race time, the rider must continuously manage gait and speed to optimise and maintain the horse's functional and health status. Although performed at submaximal speeds, endurance races result in 7-10 h of metabolic and locomotor stress, leading to different sources of potential failure. In such events, the horse is examined by veterinarians at predefined 'vet gates', during and at the end of the race. Elimination for lameness and metabolic reasons occurs in 31.8 and $10.8 \%$, respectively, of all starting horses [1]. Although fatigue in endurance racing is well described [1-3], most studies focus on the horse rather than on the 2 interdependent horse and rider components, whose interactions determine the final outcome of the race and influence the horse's health status.

There are few recent studies that emphasise the horse-rider interaction. On the one hand, the added body mass and the rider expertise level are reported to influence the horse's motion pattern regularity [4-6], back loading [7], limb kinematics [8,9] and degree of lameness [10]. On the other hand, the rider's energy expenditure may be affected by the horse's gait [11], the riding technique $[12,13]$ and the rider expertise level [5]. The 2-point technique is reported to be beneficial for the horse's back loading and speed $[14,15]$, although metabolically and mechanically costly for the rider [13]; inevitably, a compromise will be established. During endurance races, the use of different combinations of gaits and riding techniques may thus be expected to depend on the racing strategy as well as horse and rider fatigue status. These observations motivated us to investigate the influence of the expertise level on the evolution of the biomechanical horse-rider interaction during 91-124 km endurance races.

In our recent study [16] and in line with others [5,15,17], it has been shown that the concepts, methods and tools of self-organising dynamic systems offer new potential for understanding horse-rider coupling. The coupling concept, inspired from the dynamic approach of complex systems [18], is appropriate for the analysis of the horse and rider vertical displacements. In particular, 4 patterns of horse-rider coupling, reflecting the use of 2 riding techniques per gait (trot and canter), were characterised by distinct 'signatures', which could be recognised among the different dyads. Our previous study, however, did not analyse the time evolution of these patterns.

The present study therefore aimed at differentiating, both quantitatively and qualitatively, elite and advanced dyads during endurance races. First, it was necessary to test whether the use of 2 synchronised accelerometers would allow such analysis for each of the thousands of strides of endurance races. Our first hypothesis was that, by aiming to win the race by increasing speed while limiting stress applied to the horse's back, elite dyads make greater use of the 2-point canter than advanced dyads. Our second hypothesis was that the emergence of fatigue results in larger intradyad variability in horse-rider coordination, as well as increased rider heart rate, especially in the advanced dyads.

\section{Methods}

\section{Horse-rider dyads}

Five elite dyads (ELITE), with $\geq 3$ international podiums within the last 5 years, and 5 advanced dyads (ADV), with $<3$ international podiums, enrolled in the study. The ELITE group included 2 female and 3 male riders (mean age $=29 \pm 5.7$ years; body mass $=59 \pm 11.6 \mathrm{~kg}$; and height $=$ $1.71 \pm 0.14 \mathrm{~m}$ ), 2 geldings and 3 mares (age $=9 \pm 3$ years; body mass $=$ $371 \pm 65 \mathrm{~kg}$; and height at withers $=1.57 \pm 0.06 \mathrm{~m}$ ). The ADV group included 4 female and one male riders (mean age $=30 \pm 16$ years; body mass $=67 \pm 8 \mathrm{~kg}$; and height $=1.72 \pm 0.07 \mathrm{~m}$ ) and 4 geldings and one mare (age $=7 \pm 1$ years; body mass $=392 \pm 39 \mathrm{~kg}$; and height at withers = $1.54 \pm 0.02 \mathrm{~m})$. 


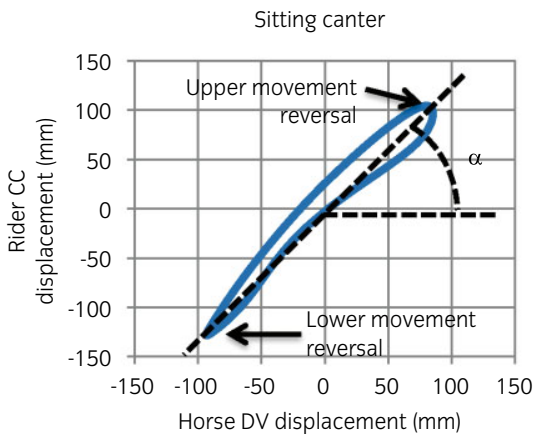

Rising trot

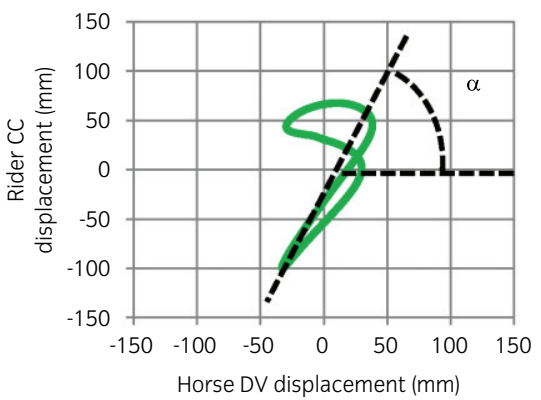

\section{Racing conditions}

Data were recorded during 10 different international (CEI*/CEI**) equestrian competitions (from April 2012 to February 2013). The distance to be covered in a day varied from 91 to $124 \mathrm{~km}$ and included roads and forest track conditions, with overall elevation differences ranging from \pm 504 to $\pm 3268 \mathrm{~m}$. Each race was subdivided into 3 or 4 loops (L1-L4) varying in distance from 20 to $42 \mathrm{~km}$. Veterinary inspections or 'vet gates' took place before the first loop and after each loop. To be ranked, the horse had to pass each of these inspections. To ensure spontaneous patterns of coordination, no instruction was given to the rider concerning the specific gait and riding techniques to adopt.

\section{Data acquisition}

Horse-rider vertical movements were recorded using 2 triaxial (3-dimensional) accelerometer data loggers, namely Locometrix ${ }^{\oplus a}$ and Equimetrix ${ }^{\oplus b}$. To allow subsequent synchronisation of the rider's and horse's accelerometric data, the 2 accelerometers were hit against each other on the vertical axis before and after completion of each loop. Each pair of accelerometers had previously been checked over $7 \mathrm{~h}$ of static recordings to allow a precise correction of any potential time lag. Conforming to the recommended instructions for their use, the Equimetrix ${ }^{\circledast}$ was fixed under the caudal part of the horse's sternum and the Locometrix ${ }^{\circledast}$ onto a neoprene kidney belt worn by the rider. Sampling rate was set at $100 \mathrm{~Hz}$ per axis with an anti-aliasing filter (cut-off frequency of $50 \mathrm{~Hz}$ ). Riders were also instrumented with a global positioning system training device/heart rate monitor (Garmin 310XT $\mathrm{HR}^{\mathrm{c}}$ ) to record instantaneous speed and rider heart rate during the entire race. The Garmin data acquisition was initiated at the same time as the accelerometer recordings. All data were then transferred to a laptop computer for further analysis. The detailed set-up is described in Viry et al. [16].

\section{Accelerometric data processing and analysis along the vertical axis}

The analysis of the acceleration signals of the 10 horses and riders concentrated on their 'vertical' component, i.e. dorsoventral (DV) for the horse and craniocaudal (CC) for the rider. Analysis algorithms were developed in the Matlab environment (version $7.10^{d}$ ).
Two-point canter

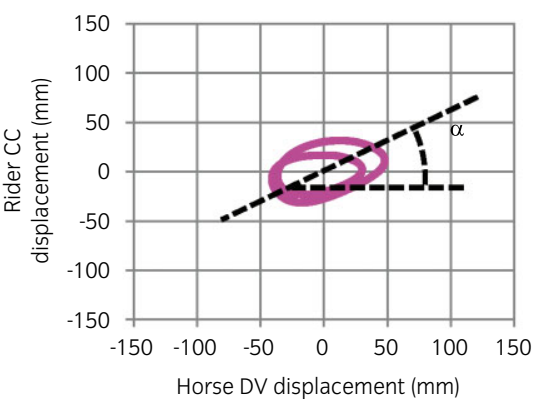

The horse and rider displacements were obtained by double integration using cumulative trapezoidal numerical integration and applying a Butterworth bandpass filter (1-12 Hz). As reported by Barrey et al. [19], given that horse DV displacement presents 2 repeated oscillations per stride at the trot (2 contact and flight phases) vs. one at the canter, the frequency of the horse DV displacement can be used to determine the gait patterns and thus to differentiate the trot from the canter. For the trot and canter, mean stride frequencies are around 1.5 and $1.8 \mathrm{~Hz}$, with corresponding DV oscillations that average 3 and $1.8 \mathrm{~Hz}$, respectively (see Viry et al. [16] for details about stride identification).

To capture the horse-rider coupling patterns, their spatiotemporal relationships over stride cycles were represented within a displacement/displacement space (Lissajous plots; see Fig 1 for illustration and Viry et al. [16] for more details). From the resulting Lissajous plots (for each and every stride), an analysis of the inclination angle (angle $\alpha$ in Fig 1) led to the identification of 2 distinct angle $\alpha$ ranges per gait, with the smaller angles being attributed to the smaller rider CC displacements in the 2-point technique (see Viry et al. [16] for more details). The angle $\alpha$ was thus used to classify each stride into the 2-point vs. the rising trot and the 2-point vs. the sitting canter techniques (Fig 1). For simplicity, the 'combinations of gait and riding techniques' will be referred to as 'techniques' hereafter.

An additional analysis was performed to quantify the potential use of a 5th technique, the rising canter, which would not be detected by the previous stride analysis because it involves alternating strides of sitting and 2-point canter (1:1). To avoid other conditions, such as riding technique transitions and other types of alternating pattern $(2: 1$, $3: 2, \ldots$.), being misidentified as rising canter, the classification as rising canter required a minimum of 6 successive alternating strides in these 2 techniques.

Our analysis quantified, for each loop, the number of strides performed for each technique. However, as the rising canter was absent in 3 dyads and did not represent more than $0.4 \%$ in the others, this technique was not taken into further consideration. The proportional use of the other 4 techniques was thus calculated for each loop and for the entire race. Each technique was also characterised by the associated mean horse speed and rider heart rate values per loop and for the whole race.

The quality of the horse-rider coupling can be revealed by the relative phase (RP). As shown in Figure 1, the RP value was obtained for each stride by measuring the time delay between the horse and rider at the lowest 
point of their relative vertical displacements $\left(T_{\min }\right.$ (rider) $-T_{\min }$ (horse)). This time difference was converted into a phase shift in degrees by applying the classic formula used for calculation of discrete RP [20]:

$$
\mathrm{RP}=\frac{T_{\min }(\text { rider })-T_{\min }(\text { horse })}{\text { Stride duration }} \times 360
$$

Each technique was then characterised by its mean RP and intradyad variability for each loop of the race.

As the endurance races included either 3 or 4 loops, each race was subdivided into 3 sections (BEG, MID and END) that corresponded to the first, the intermediate and the last loops, respectively. For the races composed of 4 loops, the MID values corresponded to the average of the second and third loops. The MID values of 4 of the present horse-rider dyads (2 from each group) featured also in the study by Viry et al. [16].

\section{Data analysis}

Statistical analyses were performed with Statistica (version 10)e Intergroup differences in physical characteristics (age, gender, body mass and height for both rider and horse), in racing condition (distance) and in global racing speed were tested by using a Mann-Whitney U-test for independent samples. Once the strides had been identified for each of the 4 techniques (sitting canter, 2-point canter, rising trot and 2-point trot) and after a Lilliefors test for normality of the data and a Levene test for equality of variances between the 2 groups of riders, most dependent variables (specific speed per technique, rider's heart rate, intradyad variability of angle $\alpha$, mean relative phase and its intradyad variability) were tested by a two-way ANOVA S5[G2] × Ti3, with $S$ being the subject, G the Group (ELITE, $A D V)$ and Ti the Time (BEG, MED, END). Post hoc tests were performed by means of Bonferroni procedures. Intertechnique differences for the previously mentioned dependent variables were tested independently of Group and Time by Student's paired $t$ tests with a Bonferroni correction for multiple comparisons. Chi-square tests were performed for each group separately in order to analyse whether the proportion of riding technique was modified as a function of Time. In all tests, the significance threshold was set at $P=0.05$.

\section{Results}

\section{Physical characteristics of horse-rider dyads and racing conditions}

No significant difference was found between the 2 groups.

\section{Global racing speed and specific speed per technique}

The ANOVA revealed a significant main effect of Time $(P<0.001)$ and interaction between Time and Group $(\mathrm{P}<0.01)$. On average, the global racing speed increased from $18.1 \pm 1.5 \mathrm{~km} / \mathrm{h}$ at BEG to $19.9 \pm 2.5 \mathrm{~km} / \mathrm{h}$ at END $(P<0.001)$, with a larger increase in the ELITE dyads, whose racing speed increased from $18.2 \pm 1.5 \mathrm{~km} / \mathrm{h}$ at BEG to $21.0 \pm 2.8 \mathrm{~km} / \mathrm{h}$ at END $(P<0.01)$. As shown in Figure 2 , both riding techniques with canter gait were characterised by faster speeds than the trot $(P<0.01)$ and by an increasing speed during the race $(P<0.001)$.

\section{Rider heart rate}

The analysis revealed for each of the 4 techniques a significant interaction between Time and Group $(\mathrm{P}<0.05)$, with an increase of the mean heart rate for the ELITE riders from $144 \pm 12$ beats/min at BEG to $158 \pm 9$ beats/min at END $(P<0.01)$.

\section{Proportion of each technique}

The Chi-square analysis revealed a significant Technique effect for ELITE but not for ADV $(P<0.05)$. As can be observed in Figure 3, the ELITE presented an increasing use of the sitting canter during the race. Independently of

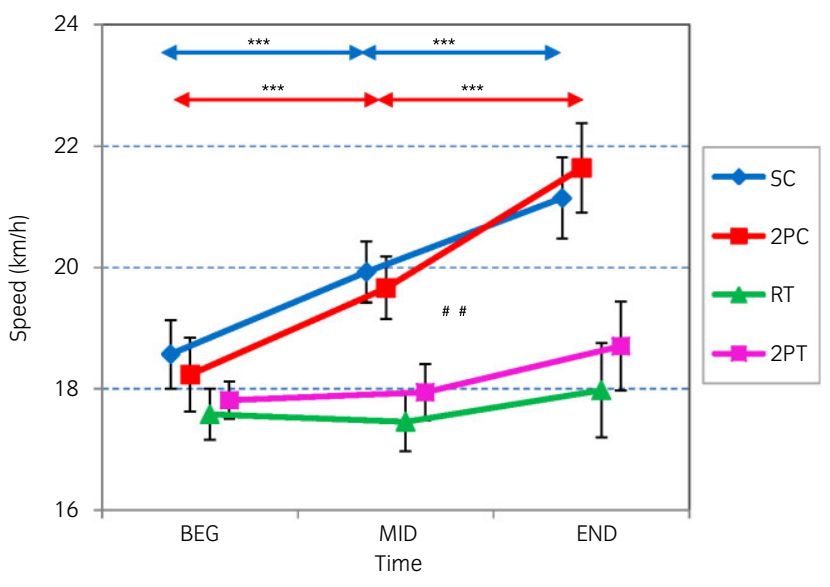

Fig 2: Time influence on speed ( \pm s.e.) depending on the technique. BEG, first loop; END, last loop; MID, intermediate loop(s); RT, rising trot; SC, sitting canter; 2PC, 2-point canter; 2PT, 2-point trot. ***Significant difference between time periods of the race at $P<0.001$. \#\#P<0.01 significant difference independently of Time between the 2 canter and trot techniques.

the group, the proportion of the 2-point trot $(11.0 \pm 9.8 \%)$ was lower in comparison to the other techniques, except for the sitting canter at BEG.

\section{Intradyad variability of angle $\alpha$}

Independently of Group and Time, Student's paired $t$ test revealed a larger variability in the sitting canter than in other techniques and the smallest variability in the 2 -point canter $(\mathrm{P}<0.01)$. Within each gait, the variability was reduced in the 2-point technique in comparison to the others $(P<0.01)$.

\section{Mean relative phase and intradyad variability}

Independently of Time and Group, all techniques differed in their mean RP value $(P<0.05)$, with the smallest RP being observed at the sitting canter and the largest at the 2-point trot (Fig 4). Within each gait (trot vs. canter), the 2-point technique was associated with a larger RP value than the other technique $(P<0.05)$. The mean RP analysis revealed a significant main Time effect as well as a significant interaction between Time and Group $(P<0.05)$. As shown also shown in Figure 4, the ELITE group was characterised in 3 of the 4 techniques (sitting canter, rising trot and 2-point trot) by higher mean $R P$ values at BEG in comparison to MID and END $(P<0.05)$. This differed from the ADV group, whose RP values did not change significantly throughout the race.

The intradyad variability analysis also revealed a main significant effect of Time $(P<0.05)$; independently of the Group, the intradyad RP variability increased from BEG to END in the 2-point canter technique (Fig 5). Within each gait (trot vs. canter), the 2-point technique was associated with larger RP variability than the other technique $(\mathrm{P}<0.01)$. When expressed as the absolute time delay between horse and rider at their respective vertical displacement minima, the intradyad variability in the 2-point canter technique varied from $16 \pm 6$ to $20 \pm 9$ ms during the race.

\section{Discussion}

In agreement with our previous findings [16], these data confirmed the possibility of using 2 synchronised accelerometers to identify the techniques adopted for each of the 25,000-45,000 horse strides per endurance race. When considering the proportional use of each technique, the rising canter was characterised by its minimal use $(<0.4 \%)$ in both groups and by its absence for 3 of the dyads. As suggested by Liesens [21], this confirmed the use of 4 major techniques in endurance races. In agreement also with our earlier observations [16], the 2-point trot proportion remained for both groups close to $11 \%$. The present study also demonstrated the appropriate use of the RP (mean and intradyad variability) to evaluate the quality of the horse-rider coordination throughout the race. For instance, the sitting canter was characterised for 


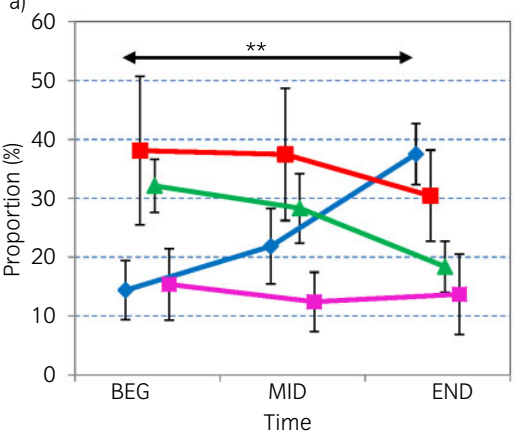

b)

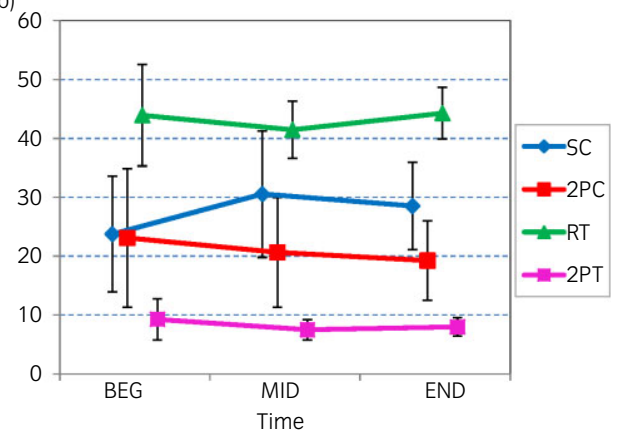

Fig 3: Time influence on the mean ( \pm s.e.) proportional use of each riding technique by the ELITE and ADV ( $a$ and $b$, respectively). BEG, first loop; END, last loop; MID, intermediate loop(s); RT, rising trot; SC, sitting canter; 2PC, 2-point canter; 2PT, 2-point trot. $\star * P<0.01$ between times of the race.

all dyads by the largest intradyad variability in angle $\alpha$ and by the lowest mean RP value. These observations suggest that the riders were able to adjust and synchronise their vertical displacement with the horse's motion in order to be 'in phase' at the lowest point of their respective movement reversal. Likewise, Lagarde et al. [5] suggested that the contact between the horse and the rider (through the saddle) might haptically convey effective communication between them

Our first hypothesis was that ELITE would make greater use of the 2-point canter than ADV, in order to combine high speed and limited stress

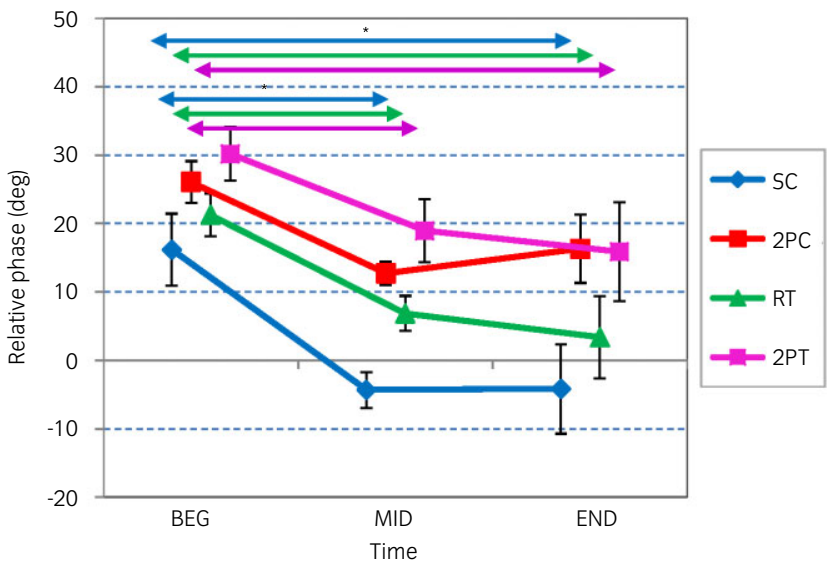

Fig 4: Evolution during the race of mean ( \pm s.e.) relative phase values for ELITE dyads. BEG, first loop; END, last loop; MID, intermediate loop(s); RT, rising trot; SC, sitting canter; $2 \mathrm{PC}, 2$-point canter; $2 \mathrm{PT}, 2$-point trot. ${ }^{\star} \mathrm{P}<0.05$.

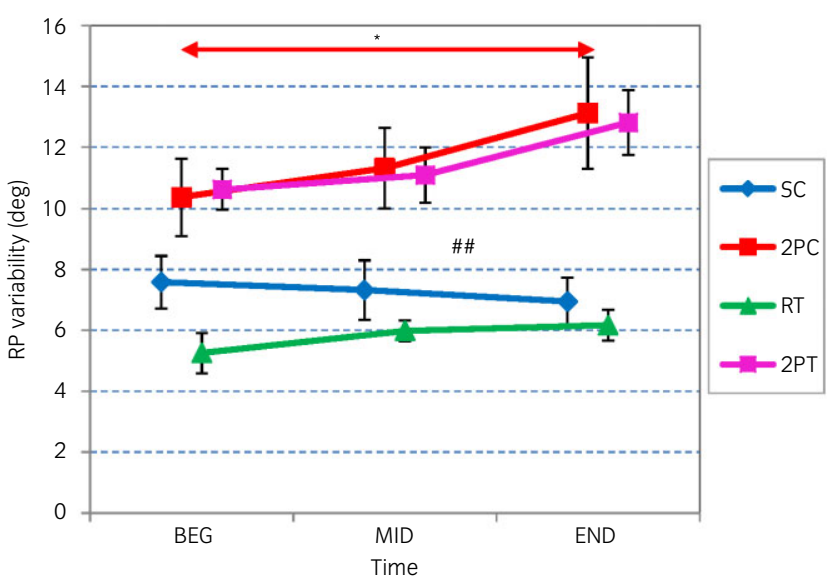

Fig 5: Evolution during the race of the mean ( \pm s.e.) intradyad variability in the relative phase. BEG, first loop; END, last loop; MID, intermediate loop(s); RP, relative phase; RT, rising trot; $\mathrm{SC}$, sitting canter; $2 \mathrm{PC}, 2$-point canter; $2 \mathrm{PT}$, 2-point trot. ${ }^{*} \mathrm{P}<0.05, \# \# \mathrm{P}<0.01$ significant difference independent of Time between the 2 canter and trot techniques. to the horse's back. Although this technique averaged $28.2 \%$ in all dyads and $37.7 \%$ in the ELITE, no significant intergroup difference was found, and its proportion remained stable throughout the race. This stability contrasted with the increasing use (from 14.4 to $37.5 \%$ ) of the sitting canter by the ELITE. Two nonexclusive explanations can be proposed. On the one hand, the 2-point technique is reported to result, for the rider, in substantial additional mechanical work, high metabolic cost and significant changes in cardiorespiratory response [13]. This is supported by the present increase in intradyad RP variability in the 2-point canter, which indicates that the 2-point canter may have become more constraining than the sitting canter. In this light, the absence of a significant rise in heart rate due to race-induced fatigue seems surprising but can be attributed to various confounding factors, such as the occurrence of numerous transitions between techniques that may have interfered. On the other hand, the delayed and prolonged preferred use of the sitting canter could be attributed to the effective synchronisation (smallest RP) that this technique allows between horse and rider despite the progressive development of fatigue.

Our second assumption was that the emergence of fatigue might result in larger intradyad variability in horse-rider coordination and in increased rider heart rate, especially in the ADV. Differing partly from these expectations, intradyad RP variability increased in the 2-point canter, but to a similar extent for all dyads. It remains questionable whether part of the increased intradyad variability resulted from the increase in speed, especially at the canter gait. The same remark applies to the mean heart rate, which increased in the ELITE rather than in the ADV riders. The absence of clear signs of fatigue in the ADV is attributed to the remarkable stability that they demonstrated during the entire race in the proportional use of the 4 techniques. Given that the measurements took place in endurance races performed at free speed, this was rather unexpected. Considering their additional stability in the mean RP values, these observations suggest that the strategic aim of the ADV riders was to secure their horses to pass the vet gates and to finish, as they did, rather than to win the race. The ELITE presented instead an initially higher mean $\mathrm{RP}$ in 3 of the 4 techniques. This value became minimal at mid-race and remained as such thereafter. This is expected to reflect the riders' aim to slow their horse down during the first loop to maintain the horse's functional status and health for the rest of the race. This is partly confirmed by their significant increase in sitting canter and in racing speed towards the end of the race, which allowed them to finish consistently within the top quarter of the participants.

\section{Conclusion}

By using 2 synchronised accelerometers, this study aimed to differentiate, both quantitatively and qualitatively, elite and advanced dyads during international endurance races. In this respect, the interest and originality of the present study is to demonstrate that, despite the lack of detailed information about the racing constraints, one can differentiate groups of different expertise levels, characterise racing strategies through their proportional use of the different gait and riding techniques, and reveal potential signs of fatigue in the horse-rider coupling during the course of the races. This study is still somewhat limited by the small number of participating horse-rider dyads. In particular, further investigations should be planned to compare dyads within the same endurance races. 


\section{Authors' declaration of interests}

No competing interests have been declared.

\section{Ethical animal research}

Before their enrolment in the study, all riders were fully informed of the entire protocol and signed a consent form. This study was approved by the ethics committee of Aix-Marseille University and it conformed to the provisions of the Declaration of Helsinki.

\section{Sources of funding}

Sylvain Viry was supported by a grant of the French National Agency of Technological Research (ANRT), no. 720/2009. This study was sponsored by a grant from the Institut Français du Cheval et de l'Equitation (IFCE).

\section{Acknowledgements}

The authors gratefully acknowledge J. P. Frances and his team from 'Stables JPF' for their constructive involvement in the entire project, $\mathrm{T}$. Coyle for proofreading the manuscript and M.-D. Giraudo for valuable contribution to the statistical analysis.

\section{Authorship}

S. Viry, E. Berton, M. Laurent and C. Nicol contributed to study design. S. Viry and J. P. Frances contributed to study execution. S. Viry, M. Laurent and C. Nicol contributed to data analysis and interpretation. S. Viry, J. B. De Graaf and C. Nicol contributed to the preparation of the manuscript. All authors gave their final approval of the manuscript.

\section{Manufacturers' addresses}

aINRA, SGQA, Jouy-en-Josas, France.

${ }^{b}$ Centaure Metrix, Lisses, France.

'Garmin, Schaffhouse, Switzerland.

${ }^{\mathrm{d}}$ MathWorks, Natick, Massachusetts, USA

eStat-Soft, Tulsa, Oklahoma, USA.

\section{References}

1. Nagy, A., Murray, J.K. and Dyson, S. (2010) Elimination from elite endurance rides in nine countries: a preliminary study. Equine Vet. J. 42, Suppl. 38, 637-643.
2. Barnes, A., Kingston, J., Beetson, S. and Kuiper, C. (2010) Endurance veterinarians detect physiologically compromised horses in a $160 \mathrm{~km}$ ride. Equine Vet. J. 42, Suppl. 38, 6-11.

3. Fielding, C.L., Meier, C.A., Balch, O.K. and Kass, P.H. (2011) Risk factors for the elimination of endurance horses from competition. J. Am. Vet. Med. Assoc. 239, 493-498.

4. Peham, C., Licka, T., Schobesberger, H. and Meschan, E. (2004) Influence of the rider on the variability of the equine gait. Hum. Mov. Sci. 23, 663-671.

5. Lagarde, J., Kelso, J.A., Peham, C. and Licka, T. (2005) Coordination dynamics of the horse-rider system. J. Mot. Behav. 37, 418-424.

6. Schöllhorn, W.I., Peham, C., Licka, T. and Scheidl, M. (2006) A pattern recognition approach for the quantification of horse and rider interactions. Equine Vet. J. 38, Suppl. 36, 400-405.

7. de Cocq, P., Clayton, H.M., Terada, K., Muller, M. and van Leeuwen, J.L. (2009) Usability of normal force distribution measurements to evaluate asymmetrical loading of the back of the horse and different rider positions on a standing horse. Vet. J. 181, 266-273.

8. Clayton, H.M., Lanovaz, J.L., Schamhardt, H.C. and van Wessum, R. (1999) The effects of a rider's mass on ground reaction forces and fetlock kinematics at the trot. Equine Vet. J. 31, Suppl. 30, 218-221.

9. de Cocq, P., van Weeren, P.R. and Back, W. (2004) Effects of girth, saddle and weight on movements of the horse. Equine Vet. J. 36, 758-763.

10. Licka, T., Kapaun, M. and Peham, C. (2004) Influence of rider on lameness in trotting horses. Equine Vet. J. 36, 734-736.

11. Devienne, M.F. and Guezennec, C.Y. (2000) Energy expenditure of horse riding. Eur. J. Appl. Physiol. 82, 499-503.

12. Westerling, D. (1983) A study of physical demands in riding. Eur. J. Appl. Physiol. 50, 373-382.

13. Trowbridge, E.A., Cotterill, J.V. and Crofts, C.E. (1995) The physical demands of riding in National Hunt races. Eur. J. Appl. Physiol. 70, 66-69.

14. Peham, C., Kotschwar, A.B., Borkenhagen, B., Kuhnke, S., Molsner, J. and Baltacis, A. (2010) A comparison of forces acting on the horse's back and the stability of the rider's seat in different positions at the trot. Vet. J. 184, 56-59.

15. Pfau, T., Spence, A., Starke, S., Ferrari, M. and Wilson, A. (2009) Modern riding style improves horse racing times. Science 325, 289.

16. Viry, S., Sleimen-Malkoun, R., Temprado, J.-J., Frances, J.-P., Berton, E., Laurent, M. and Nicol, C. (2013) Patterns of horse-rider coordination during endurance race: a dynamical system approach. PloS One $\mathbf{8}$, e71804.

17. Wolframm, I.A., Bosga, J. and Meulenbroek, R.G.J. (2013) Coordination dynamics in horse-rider dyads. Hum. Mov. Sci. 32, 157-170.

18. Kelso, J.A.S. and Fuchs, A. (1995) Self-organizing dynamics of the human brain: critical instabilities and Sil'nikov chaos. Chaos 5, 64-69.

19. Barrey, E., Hermelin, M., Vaudelin, J.L., Poirel, D. and Valette, J.P. (1994) Utilisation of an accelerometric device in equine gait analysis. Equine Vet. J. 26. Suppl. 17, 7-12.

20. Zanone, P.G. and Kelso, J.A. (1992) Evolution of behavioral attractors with learning: nonequilibrium phase transitions. J. Exp. Psychol. Hum. Percept. Perform. 18, 403-421.

21. Liesens, L. (2010) Endurance, Le livre d'un cavalier, Pour les cavaliers. p 360. 